\title{
ADOLESCENT FRONTAL LOBE BRAIN DEVELOPMENT: EFFECTS OF SOCIAL AND ECONOMIC DEPRIVATION AND IMPLICATIONS FOR INTELLECTUAL ASSESSMENT, ACADEMIC REMEDIATION, AND COURT CASE DISPOSITION
}

\author{
Michael Lindsey \\ JD, PhD, Adjunct Professor Psychology Department, Southern Methodist University, President-Nestor \\ Consultants, Inc., Dallas, Texas (USA)
}

\begin{abstract}
Neuroscience has documented the substantive growth of frontal lobe gray matter during the adolescent years, similar to the brain growth spurt in early childhood - both precursors of preparation for quantitative and qualitative adaptive learning. Several United States Supreme Court decisions (Roper v. Simmons; Graham v. Florida; JDB v. North Carolina; Miller v. Alabama) have affirmed the historical chronological age of 'majority' being 18 years old, is inconsistent with what it means to be an adult. Mature cognitive processing is more appropriately characterized by the "Jean Piagetian" formal operations stage, i.e., abstract thinking, logical thinking, decision-making, and long-term planning. Formal operations is now acknowledged to be achieved during a young adult's mid-20's years of age.

"Adult" (mature) cognitive functioning is a combination of adequate brain tissue (gray matter), and learning (white matter). White matter is accumulated as a person grows, develops adaptive schema, has experiential practice, is taught, learns from modeling, and observations. We can thus infer that the more diverse are these ways of 'becoming an adult,' the more competent the young adult will be.

Current educational and IQ normative data we have on adolescents is from majority (i.e., non-ethnic majority) youth. Not yet answered is what are the norms for ethnic minority young adults (mid -20's), who have social, economic, academic, and/or experiential deprivation?

If such life experiences result in less white matter, and less complex white matter - are consequently, the normative data on "deprived" ethnic minority youth significantly different from majority youth? If yes, the implications are enormous for such issues as: (1) educational remediation; (2) IQ testing, (3) juvenile court case disposition, (4) the youth's lifelong success, (5) citizenship behaviors, (6) self, and (7) familial sufficiency.

This workshop will explore these complex issues, and make recommendations for the following next steps: empirical data collection, 'intervention' program changes, and policy reforms.
\end{abstract}

Keywords: Brain, adolescent, IQ, judges. 